\title{
Opportunities and Challenges for Teacher Professional Development: A Case of Collaborative Learning Community in South Korea
}

\author{
Minjeong Park $^{1}$ \& Kyunghee $\mathrm{So}^{2}$ \\ ${ }^{1}$ Department of Educaiton, College of Educaion, Chung-Ang University, Seoul, South Korea \\ ${ }^{2}$ Department of Educaiton, College of Education, Seoul National University, Seoul, South Korea \\ Correspondence: Kyunghee So, Department of Education, College of Education, Seoul National University, 1 \\ Gwanak-ro, Gwanak-gu, Seoul 151-742, South Korea. Tel: 82-2-880-7641. E-mail: sohee@snu.ac.kr
}

$\begin{array}{rr}\text { Received: April 22, } 2014 & \text { Accepted: May 25, } 2014 \quad \text { Online Published: June 25, } 2014 \\ \text { doi:10.5539/ies.v7n7p96 } & \text { URL: http://dx.doi.org/10.5539/ies.v7n7p96 }\end{array}$

\begin{abstract}
This study investigates how characteristics of a collaborative professional learning activity support and hinder teacher learning and growth by examining the experiences of three Korean secondary teachers who participated in a school-initiated collaborative teacher learning project. The findings demonstrated that this learning opportunity supported teachers in their learning and professional development in the following ways. First, teachers experienced professional growth through collaborative learning with colleagues. Second, teachers learned to self-reflect on their classes. Third, the program fostered an inquiry stance toward teaching. Also identified are some of the obstacles encountered, such as time constraints, psychological barriers, and the lack of a discussion culture.
\end{abstract}

Keywords: Korean teachers, learning community, professional development, teacher learning

\section{Introduction}

Educational reform movements in Korea and around the world are setting ambitious goals for student learning. Many factors contribute to achieving these goals. However, changes in classroom practices demanded by the reforms ultimately rely on teachers (Fullan \& Miles, 1992; Spillane, 1999). Changes of this magnitude will be difficult to carry out without support and guidance for teacher development (Ball \& Cohen, 1999; Putnam \& Borko, 2000; Wilson \& Berne, 1999). This realization has led educational scholars and policy makers to put great emphasis on improving teacher professional development as a cornerstone of education reform (Fullan, 2000; McLaughlin \& Talbert, 2006).

Cohen and Hill (2000) conducted a study of mathematics teaching in California by examining data on teachers' professional development experiences and school-level data on student performance on a mathematics test administered statewide. They found that, controlling for the characteristics of students enrolled, mathematics achievement was on average higher in schools where teachers had participated in extensive professional development focusing on methods of teaching specific mathematics content, compared to the achievement in schools where teachers had not. Kennedy (1998) found similar results in a review of well-designed experimental studies of the relationship between professional development and student achievement in mathematics and science. In Korea, Seo (2009) also argued that when teachers developed a professional learning community, it not only enhanced their knowledge base, but also had a significant impact on their classroom work. Indeed, the growing number of professional development efforts that center on teachers carefully examining and analyzing classroom practice is a testimony to this census (Ball \& Cohen, 1999; Campbell et al., 2004; Cochran-Smith \& Lytle, 2009; Garet, 2001; Opfer \& Pedder, 2010).

Although many studies have evidenced that effective teachers can be fostered by continuing professional development, they rarely address questions such as what are powerful ways for teachers to learn and grow through professional development? What challenges and dilemmas do teachers encounter while participating in professional development? This study investigates the conditions and qualities of collaborative professional learning activities that support or hinder teacher learning and growth by examining the experiences of three Korean elementary teachers who participated in a school-initiated collaborative teacher learning project.

The result of this study will reveal the potential benefits of helping teachers learn and grow through collaborative 
teacher learning, and also flesh out some challenges to professional development. This study also will support researchers and educators in understanding how to develop and enact teacher collaborative learning activities as an alternative to short-term, top-down, generic, or formulaic approaches.

\section{An Examination of the Research-Base for Teacher Professional Development}

Traditional teacher professional development is based on a hierarchical model of expertise and a transmission model of teaching; that is, one goes to experts and "receives" professional knowledge from them. Professional development in this traditional paradigm involves knowledge that is well organized, prepared, and presented to the learner. Many teacher professional development programs have operated on exactly this model. Teachers come to workshops, attend classes, or go online in order to obtain expert knowledge. It is assumed that armed with this knowledge, teachers can then change the way they teach.

However, knowledge is not an object to be put in a drawer and pulled out in necessary situations (Fahey \& Prusak, 1998). Knowledge is "in constant flux and change. It is central to day-to-day doing and being. Individuals create it and it is largely self-generating" (p. 266). Put succinctly, knowledge is effective action in situations (Brown \& Duguid, 1998). This understanding of knowledge suggests that an important part of professional development is the ability for participants to better connect with their community and jointly construct knowledge while exploring and reflecting on their practice.

In response to this perspective, current thinking and theories highlight contextual-based and socio-constructivist understandings of teacher professional development that focus on the social nature of practice and knowledge construction, and they support the notion of situating teacher learning in classroom practice. The benefits of contextual learning for both teacher education and professional development have been widely theorized (Ball \& Cohen, 1999; Hiebert et al., 2002; Kazemi \& Hubbard, 2008; Wilson, 2013). By examining this area of research, we identified three attributes of initiatives to develop and nurture professional development for teacher learning and growth.

\subsection{Collaborative Learning beyond Individual Learning}

At the heart of the process of teacher learning is the notion of community. The focus is not just on an individual teacher's learning but on collective and collaborative learning within a community context. Collaboration, particularly within a community of practice (Wenger, 1998), has been promoted as a key factor for both creating and sustaining conditions for teachers' learning (Cochran-Smith \& Lytle, 2009; Erickson et al., 2005). Collaboration is rooted in a social theory of learning within a "community of practice" which is a group of people who share a concern for or an interest in something they do and, through regular interaction, learn how to do it better (Wenger, 1998). As early as 1938, Dewey examined how teachers' knowledge, beliefs, and practices are shaped through engagement with communities of practice. Similarly, Lave and Wenger (1998) showed how learning takes place through the lived experience of social participation. Wenger (1998) describes communities of practice as a theory of situated experience that "mostly address[es] the interactive relations of people with their environments" (p. 13).

According to these perspectives, collaboration among individual community members allows them to view one another as part of a collective whole working toward the joint goals of the community and its members. As such, a community is an interdependent system defined by the collaborative efforts of its members (Wenger, 1998). Collaborative learning is evident through collective knowledge creation whereby the participants of a learning community interact, engage in serious dialogue, and deliberate about knowledge, interpreting it communally and then distributing it among them.

Recently, teacher educators have been looking toward the design of communities of practice as environments to support professional learning (Hord, 1997). The assumption is that effective teachers can be fostered by grounding professional development in collaborative learning communities that highlight teachers' mutual engagement in action, make them feel valued, and encourage them to talk about their different experiences and understandings. This process engages teachers in joint review and feedback while encouraging them to work together to consider, explore, and reflect on issues and approaches related to shared issues and questions.

\subsection{Inquiry-Oriented Learning}

Recent research on teacher learning has emphasized the creation of inquiry communities as central to meaningful professional development and pre-service education. Wilson and Berne (1999) criticized traditional workshop-style teacher learning for relying on "outside experts" and "boring, pre-packaged information," resulting in experiences where "teachers learn little (or at least little of worth)" (p. 174). In contrast, they described situations of more meaningful teacher learning where teachers had opportunities to work in inquiry 
communities. These approaches have pointed out that professional development is sustained and nurtured when teachers engage in cycles of inquiry that involve action and reflection (Butler \& Schnellert, 2008; Cochran-Smith \& Lytle, 2009).

A key concept related to teachers' inquiry learning concerns how teachers' iterative cycles of inquiry involve self- and co-regulation of practice and learning (Butler \& Schnellert, 2008; Hobson, 2001). This process entails teachers having a voice in determining and developing learning opportunities and activities, constructing and enacting inquiries and action plans, and monitoring their actions. In this manner, Cochran-Smith and Lytle (2009) have noted that "practitioner inquiry" leads teachers to reflect on and refine their practices. They posit that "a unique feature of the questions that prompt practitioners' inquiry is that they emanate from neither theory nor practice alone but from critical reflection on the intersections of the two" (p. 42).

In particular, teacher's inquiry learning includes "reflective dialogue" (Louis et al., 1995) involving the application of new knowledge in a sustained manner; examination of practice through mutual observation and case analysis (Newmann \& Wehlage, 1995); conversion of tacit knowledge into shared knowledge through interaction (Fullan, 2001); and the application of new ideas to problem solving and solutions addressing students' needs (Hord, 1997). A focus on inquiry can support teachers to consider and explore multiple pedagogical methods, and to view problems from many perspectives. On this point, Cochran-Smith and Lytle (1999) speak of "teacher research as an agency for classroom and school change" (p. 18). The premise of their position is that when teachers engage in inquiry and generate local knowledge through their classroom-based inquiries, they become empowered to address larger educational issues and problems encountered in their own practice.

\subsection{Practice-Based Learning}

Professional development, though well intentioned, is often perceived by teachers as fragmented, disconnected, and irrelevant to the real problems in the classroom. Most teachers are dissatisfied with professional learning opportunities because of the discrepancy between the learning content and their experience dealing with real problems in the classroom. Recent teacher education has emphasized learning opportunities that focus on the real world of the classroom and are integrated into teachers' everyday work (Cohen \& Hill, 2000; Mitchell, 2000; Timperley et al., 2007). Attention to the practical problems teachers have encountered plays a crucial role in this current climate of teacher professional development.

Challenging traditional conceptions of researcher-as-theory-creator and teacher-as-theory-applier, many researchers have described teachers as knowledge-makers who tailor their practice using wisdom derived from the situation at hand (Cochran-Smith \& Lytle, 1993). Schon (1983) argues that teachers' practice-based learning does not involve the "use of techniques derived from applied research" (p. 41). Teachers theorize their own work and construct the meaning of their activity, while exploring various aspects of their professional context in relation to their practice and theory. Many studies report that the use of records of practice, such as samples of student work and videotapes of lessons, in the context of teacher professional development is successful in fostering teacher learning and improved student achievement (Borko, 2004).

Regardless of these studies, many teachers do not purposefully or even consciously reflect on how their behavior relates to the complex situations in which they act (Campbell et al., 2004). The complex, situated demands of classrooms and schools do not afford teachers many opportunities to purposefully pause and reflect on what they are doing and noticing. This reality urges us to build teacher professional development programs focused on practice-based learning where teachers' understandings and practices are developed through reflective attention to how context is related to one's actions (Dewey, 1938; Lave \& Wenger, 1991; Schon, 1983).

\section{Methodology}

\subsection{Context of This Study}

For many years, Korean teachers have pursued individual learning opportunities for professional development by signing up for partial-day or day-long workshops, participating in school-based seminars, and joining professional organizations. Those learning activities are often a mélange of abstract ideas with little attention paid to ongoing support for continuous learning and evolving practices. Thus, professional development programs, though well intentioned, have often been perceived by Korean teachers as fragmented, disconnected, and irrelevant to the real problems of classroom practice (Cho, 1999; Kim, 2007). Few Korean teachers are satisfied with the quality and quantity of professional development opportunities available at their school because they are given a "one size fits all" set of professional development workshops that ignore variation in how they teach and their students learn.

Recently, there has been a burgeoning area of research encouraging us to move in a different direction with a 
deeper understanding of the kinds of conditions needed to improve teachers' practice (So, 2013; Seo, 2009). This area of research is consistent with school-based activities for teacher professional development. Teacher professional development programs in schools have become a central approach for school-wide efforts to improve the teaching profession in Korea. This school-based professional development program is generally conducted in the context of an activity called sooupyeonguhoe in Korea. The term sooupyeonguhoe literally means "in school training" and refers to an in-service training program administered by the school that brings together teachers in the same school to work on teaching improvement.

The site where this study took place had initiated a professional development program for teachers that emphasized a collaborative learning community and teacher learning through classroom experience. The teachers in this learning community made regular visits to one another's classrooms and participated in group discussions for feedback and assistance. One teacher in this collaborative learning community produced a lesson plan and made aspects of his/her practice open to peer review while other teachers observed and took notes. Immediately following the lesson, the teachers met to share feedback on teaching practices and pedagogical strategies. They engaged in detailed discussions about lesson features and instructional strategies (such as verbal and nonverbal behaviors, questioning techniques, student responses, and how the lesson flows). The group met every another week for two hours after the school day during the semester. A total of six group meetings were held. During the group meetings, teachers determined the issues and topics themselves instead of only discussing a pre-determined topic. In doing so, they made their tactic knowledge more explicit and reflected on their assumptions and beliefs about their teaching practice.

\subsection{Data Collection}

The participants in this study consisted of three secondary teachers: Lee, Cheon, and Jeong. They had engaged in this collaborative learning opportunity together for one semester. The participant teachers were selected on the basis of availability and willingness to participate. Lee is a 30 year old woman with two years of high school and a specialty in music. Joeng is a 34 year old woman with two years of high school and a specialty in math. Cheon is a 29 year old woman with four years of high school and a specialty in math. The interviews were semi-structured, guided by a set of questions and issues to be explored but mainly led by the participant teachers' responses and their understandings of this learning process (Merriam, 1998) (Note 1). We attempted to minimize our control over the course of the interview and enabled the participant teachers to speak about the topics they wanted; this gave us the flexibility to adjust to the particularities and idiosyncrasies of individual teachers' stories.

Another important source of data was the reflections teachers generated. This involved reflective writing in response to open-ended prompts about their collaborative activities and learning through this learning opportunity. This activity was designed to understand how they questioned and changed as this learning process progressed. We asked the three participant teachers to describe their experiences and feelings while participating in this learning group, how they grew as teachers through this activity, and any obstacles or dilemmas they had encountered while participating.

Along with the interview and journal writing, we conducted observations of the lessons and post-lesson discussions, which provided important contextual data. We participated in six research lessons and post-lesson discussions to observe how the teachers participated and interacted, and we took field notes.

\subsection{Data Analysis and Validation}

Data analysis was conducted by an iterative process of reading interview transcripts, reflective journal entries, and field notes (Bogdan \& Biklen, 2003). While reading, we took notes outlining our ideas about how to analyze the data and found possible themes to address. Previously, we had written open codes identifying major themes and explored these themes in analytic memos. In this process, the condensed meaning units were abstracted and labeled with a code. These themes along with the research questions formed the basis of the coding scheme. In particular, because this study was concerned with the benefits and challenges of collaborative learning opportunities in relation to teacher learning and growth, we examined each data point in relation to these themes.

For validity and reliability, we employed triangulation (i.e. convergence across data sources), member check, apparent coherence of the interpretation, and consensus among researchers. We collected data through various sources (participant observation, interview, and journal writing) and compared data from different sources. Member-checks involve allowing the participant teachers to review the data that has been collected. Each participant teacher in this study was afforded opportunities to read, correct, and make comments on the transcripts of the interviews and the themes found in this study (Lincoln \& Guba, 1985). Additionally, we discussed the interpretations of the data and the findings with our colleagues who knew a great deal about 
teacher learning and development. Such discussion served the purpose of "peer-debriefing", what Lincoln and Guba (1985) described as "exposing oneself to a disinterested professional peer to keep the inquirer honest" (p. 308). Also, a set of literature and theoretical frameworks cited herein guided our analysis. We crosschecked codes of all raw data and interpretations (Miles \& Huberman, 1994) to strengthen our analysis and integrate alternative interpretations. Along with comparisons to relevant literature, we also crosschecked discussions and participants' feedback in interview transcripts to support the reliability of our interpretations.

\section{Results}

\subsection{Opportunities for Teacher Professional Development}

\subsubsection{Growing up through Collaborative Learning with Colleagues}

As mentioned in the theoretical background discussion, collaboration has been identified as one of the most important features that foster professional development and teacher learning. Many studies have found that most school work cultures are characterized by individualism and isolation among teachers, which can lead to feelings of insecurity and a lack of desire to share ideas (Cowley \& Meehan, 2001). Similarly, Korean teachers work in isolation and rarely have a chance to observe other teachers' classes or talk about their teaching practice with colleagues (Kim, 2003; Seo, 2009). Although individual teachers may reflect on and try to improve their practice, they are left to work out problems, difficulties, and dilemmas encountered in the classroom on their own with little collaboration among peer teachers.

The participant teachers in this study, however, reported that this learning opportunity encouraged them to open up their classroom for observation and have candid discussion with peers, even though working in independent isolation was most often the norm for them. Their classrooms became less private than other teachers and outside experts observed and discussed their practice with them. The participant teachers emphasized that conversations with colleagues afforded them an opportunity to gain the insights of others about the practical problems of putting ideas into actual practice. Moreover, a valuable aspect of this learning experience was that during the process different views of teaching and learning were raised, and thus the participant teachers had the opportunity to practice critical self-reflection and hear different points of view, rather than hear only from colleagues who shared similar ideas. They valued this collaborative learning project because it provided exposure to diverse viewpoints.

For example, Lee reported that she obtained feedback on her own teaching and learned new ideas by watching how her colleagues taught. In many ways, the experienced teachers helped novice teachers like her with teaching strategies and ways of dealing with practical problems they were struggling with in day-to-day practice. Echoing Lee, Jeong also advocated for the importance of collaboration in teacher learning.

If I was not provided with this learning opportunity, as a beginning teacher, I would have merely copied the way that my previous teachers taught me. Sometimes I was not sure whether I was teaching properly; however, I had no place to get help. When I felt students misunderstood me, I really wanted to see how other teachers taught. ... This learning community offered me the opportunity to observe my peers and learn how they managed the class and how they do their teaching. In the post-lesson group meeting, we discussed the weaknesses and strengths of the observed lesson as well as the content and why such teaching strategies and teaching aids were used. It helps me grow a lot. This experience is likely to lead to improvements.

It is clear from the interviews that learning through and with colleagues is a key component to teacher learning and growth.

The growth and development that emerged from this learning process seemed to be mediated by what Hourcade and Bauwens (2002) call "collaborative reflecting." The participants reported engaging in co-reflecting that involved problem-solving where they identified challenges and brainstormed ways to adapt their practice. Several studies have demonstrated how teachers' knowledge can be developed through reflection on practice-based problems together with peer teachers, developing possible actions, and trying out and reflecting on these actions (Butler \& Schnellert, 2008; Horn \& Little, 2010; Mitchell, 2000; Snow-Gerono, 2005). While engaging in co-reflection, the teachers began to participate consciously and creatively in their own growth and development. The following interview excerpts from Lee demonstrated how collaborative reflection supported her.

Talking about teaching practices with peer teachers triggered me to think about what counts as good teaching and why. After observing peer teachers' lessons, we had post-lesson group meetings and reflected together on the object of learning, critical features, questions, activities, and approaches used in the lesson. 
Through this process, we began to make explicit teachers' tacit knowledge, decide on the next pedagogical moves, and, in some cases, step back to make theory-practice connections. This reflective process motivated me to learn about new teaching strategies, reflect on my teaching practice, and revise it.

Jeong and Cheon also stated that this learning opportunity enabled them to collaboratively study each other's teaching and participate in reflective conversations about the process of teaching and learning. For example, Cheon reported that having discussions with peer teachers about the teaching practice helped her think about what teaching strategies were working. Jeong also mentioned that she was able to think about teaching from different angles through communal dialogue and co-reflection with her peer teachers.

Their collaborative reflection work can be characterized as engagement in inquiry-based learning where they are nurtured as teachers while also collaboratively thinking about specific questions and issues with peers. Accordingly, this learning community invited the participant teachers to become inquirers and collaborators who were constantly striving to make sense of and reflect upon teaching practices and students' learning, not in isolation but rather with other teachers.

\subsubsection{Self-Reflecting on Each Own Teaching}

Related to learning by collaborative reflection discussed above, we also found that this learning community encouraged the participants to become more reflective on their own teaching practice as well as other teachers' performances. As the teachers observed their peers' classrooms and participated in post-lesson discussions, they also engaged in thinking about their own teaching practice. The following is an example of how Lee reflected on some of her lesson features, instructional strategies, and ultimately, on herself as a teacher.

I have learned the mistakes I made in my teaching while watching other teachers' lessons. I was struggling with how to manage individual and small group work in my class. I was genuinely seeking advice on engaging students in group tasks and managing their work process. I was not good at organizing groups and managing what each student accomplishes while doing group work. Watching how other teachers intervene and mediate in students' interactions, I came to realize the problem with my teaching. Other teachers become a mirror enabling me to evaluate my own work and reflect on my teaching practice. By participating in this leaning community, I could reflect on my methods of group work, teacher's intervention, tasks, class management, student motivation and participation, caring, and so on.

Similarly, Jeong made a positive comment by saying that examining her own teaching encouraged her to be thoughtful about her teaching in a way that is energizing.

Watching my videotaped lesson was a trigger for me to reflect on the strengths and weaknesses in my teaching. I thought that students did not listen to me, which resulted into students' poor academic performance. I have often blamed students for their low-achieving scores. However, after examining my videotaped class, I realized that I did not listen to students and I was insensitive to what my students wanted to do. I was a bad listener. I just listened to what I wanted to hear from the students. . . I was so nervous and impatient that I failed to acknowledge how my students learned and followed me. Although other teachers didn't perceive what was wrong with my class, I became more aware of it. There were a lot of problems that I hadn't recognized until that point. Moreover, the comments from other teachers helped me see things about my teaching that might otherwise have escaped.

Jeong's comment demonstrated that she was able to confirm, modify, or stimulate new levels of understanding about her own teaching. Performing self-analysis of her own teaching helped her break out of ineffective habits that were not in her students' best interests. Her experience resonates with research findings that reflective teachers can make connections among seemingly isolated classroom phenomena and start to take responsibility for teaching problems rather than blaming students for not learning or not being motivated to learn (Valli, 1997).

The teachers' self-reflection via this learning community goes beyond "technical reflection" (Valli, 1997) on general teaching behaviors like time-on-task, the speed of talking, gesture, and homework. Their self-reflection extended to a whole range of teaching concerns, including students, the curriculum, instructional strategies, and the rules and organization of the classroom. This learning community did not give the teachers explicit rules to follow. Rather, it helped them look back on all the important events that occurred in their classrooms and help them think carefully about these events by reading case studies of other teachers' experiences as well as their own experiences.

Research has found that teacher learning hinges on enhancing teachers' understandings of their own assumptions, reasoning, and decisions as well as their own inventions of new knowledge to fit unique and shifting classroom situations (Ball \& Cohen, 1999; Baumfield \& Butterworth, 2005). This view of teacher learning stems from the 
idea that knowledge comes from reflection and inquiry vis-à-vis each person's own practice. It implies that teachers learn to teach better by learning to construct and articulate their understandings of what is already "known". Dewey asserts that teachers already have all of the information they need, and thus should instead learn to reexamine or, in his word, "RE-search" their own experiences. Similarly, this study showed how the participant teachers have grown after engaging in "RE-search," namely, reflecting on what they have done in a different way.

\subsubsection{Fostering an Inquiry Stance toward Teaching}

By examining teachers' experiences participating in this learning opportunity, we have found that the teachers were consistently enacting an inquiry stance. We bring the concept of an inquiry stance to bear on understandings about how this leaning community expands teachers' ideas of what teaching can be. When Cochran-Smith and Lytle (1999) first introduced the notion of "inquiry as stance," they used stance to "capture the ways we stand, the ways we see, and the lenses we see through" (p. 288). Whereas traditional notions of inquiry focus on time-bounded, formal activities, inquiry as stance emphasizes habitual, ongoing awareness, that is, a disposition, mode of living, or state of being (DeStigter, 2004; Fecho, Price, \& Read, 2004).

Conceptualizing inquiry as a type of stance acknowledges the inextricable relationship between knowledge and practice. At its essence, an inquiry stance is a mode in which "teaching and thus teacher learning are centrally about forming and reforming frameworks for understanding practice" (Cochran-Smith \& Lytle, 1999, p. 290).

The participant teachers indicated that while participating in this learning opportunity, they were able to make sense of their teaching by deliberately and actively examining their practices, and eventually arrive at new ways of understanding oneself as a teacher. In Korea, teachers frequently comment on the nature of the in-service programs they are asked to attend. Many of them feel that they are instructed on theory, which ultimately gives them an inert knowledge. In contrast, the participant teachers demonstrated that this learning opportunity encouraged them to transform their perspectives and frameworks for understanding teaching in ways that extended beyond simply acquiring teaching strategies and practice-related techniques. Lee and Cheon argued that this collaborative learning opportunity enabled them to embody an inquiry stance towards teaching that went beyond traditional teacher professional development programs that focused on transmitting teaching techniques and procedures. For Lee, the stance was a journey that involved understanding who she has become as a good teacher and how this has impacted her teaching ideology.

My perspective on good teaching has been transformed after observing peer teachers' lessons and talking with peers. My initial assumption about good teaching was that the teacher lectured and students took notes. However, after observing the class using cooperative learning, my perspective has changed. The teacher introduced and explained the topic for about 15 minutes. Students then discussed the given topic in a small group and presented what they had discussed at the end of the class. The increased students' voices while talking with each other made the classroom noisy and chaotic. In the post-lesson group meeting, one of the teachers criticized the class for being noisy and messy. However, I didn't agree with him. While participating in discussion, students shared and discussed ideas with each other, which is a valuable learning opportunity. I think it was a natural class. When the teacher controlled students well, the class was quiet and students seemed to listen to the teacher. It is not always good teaching when students are quiet and listen to the teacher. I think that good teaching happens in a learning environment where students authentically learn. Even though I'm still not sure what good teaching is, it was great to have the opportunity to think over what it could be. I'm constantly thinking and reflecting on my practice.

This inquiry stance towards teaching involves teachers' moving to a new position in which they are comfortable with the continual posing of questions about their teaching. Teachers embracing an inquiry stance view these questions as opportunities to learn, and they tolerate the ambiguity of temporarily not knowing the answer. In this sense, teachers' inquiry stances towards teaching include a mindset of continuous growth and improvement (Zuidema, 2012).

Likewise, Cheon transformed her framework for teaching and learning. She had followed the typical pattern of classroom discourse with a pattern of teacher question, student response, and teacher evaluation of the response. This pattern fluctuates between lectures or presentations by the teacher and seat work, in which students work individually on study activities, often in workbooks or worksheets. After watching a discussion-based class, she realized that this type of instruction placed a premium on the transmission of information, providing very little room for the exploration of ideas, which is necessary for the development of deeper understandings. Cheon remarked that she wanted to improve her teaching practice by providing authentic learning experiences. This comment demonstrated that her inquiry stance towards teaching provided a powerful persona for her identity as a 
teacher.

The participant teachers emphasized having a sense of the "big picture" of education as a benefit of this collaborative learning community. This sense of the big picture contributed more to their personal growth and resulting classroom changes than simply conducting the external procedures provided for good teaching. While thinking aloud with peers about their teaching practice, the participant teachers encompassed a "way of knowing and being" (Cochran-Smith \& Lytle, 2009, p. 113) beyond talking about "simple" stuff and sharing or requesting teaching ideas. For the participant teachers in this study, this collaborative learning community centered on an inquiry stance where teachers constructed "knowledge-of-practice" (Cochran-Smith \& Lytle, 1999). They cultivated "knowledge-of-practice" by combining "knowledge-for-practice" gleaned from external educational researchers and "knowledge-in-practice" learned from inside their classrooms.

\subsection{Obstacles to Collaborative Teacher Learning}

\subsubsection{Time Constraint}

The perceived lack of time was a major constraint to collaborative professional development. All the teachers participating in this learning process made comments about the difficulty in finding time for the sustained conversations about teaching that this project supports. They are swamped with a lot of responsibilities such as administrative duties, attending workshops, and staff meetings. The excessive workload of Korean teachers is well documented (Kim \& Cheon, 2011; Park \& Lee, 2012). Teachers in Korea are involved in a lot of administrative and clerical work that is not related to teaching. However, collaborative professional development requires teachers' time, energy, and commitment. The participant teachers were able to participate in this learning process by cutting into time needed for other tasks. The learning group in this study met at least every another week for 2 hours, and the participant teachers met after school. Thus, they complained that this learning needed extra effort, and it was difficult to tack it on to the end of the school day.

The dynamics of collaboration involve additional issues of time, such as the obvious challenge of the participant teachers finding a common time to engage in the collaborative process. Collaborative learning times must be long enough to allow the teachers to think aloud, reframe educational issues, and to share their individual knowledge (Hardy, 2010; Pugach \& Johnson, 1990). Collaboration over an extended period of time is also needed for colleagues to develop a level of trust enabling them to fully explore their ideas and beliefs about teaching (Emery, 1996). Perseverance and dedication to the philosophy of a reflective practice is demanded of collaborative teachers. Collectively, it is important to support teachers' participation in collaborative teacher learning by allocating separate time for teacher development, finding ways for alleviating administrative work, and giving recognition to teachers' efforts in enhancing the atmosphere of learning.

\subsubsection{Psychological Barrier}

Another roadblock to the collaborative professional development involves personal risk. In Korea, opening one's classroom to peers is still a rather new practice. Korean teachers rarely have the opportunity to observe one another for the purpose of improving classroom practice. They have very little experience engaging in a professional discourse that is public and critical of their work and the work of their colleagues. This means that they are very nervous to open their classrooms to their peers and to be evaluated from peers.

In this study, it was evident that the teachers were nervous about teaching in front of others and participating in the follow-up post-lesson discussions that ensued after this public teaching. The participant teachers commonly admitted that they felt a great deal of pressure because of the peer observation. They believed that they were evaluated on their performance and felt criticized by their peers rather than learning from them. Cheon expressed her anxiety about the fear of making her teaching public by saying, "Before sharing my lesson, I was feeling sick to my stomach." Another participant teacher Jeong also commented about the psychological pressure of opening her classroom to her peers and talking openly about her teaching.

Other teachers observing and critiquing my lessons worried me. I did not want someone to point out my mistakes, which made me feel vulnerable. Most of the teachers involved felt so nervous before sharing their lesson. To overcome teachers' anxiety and self-consciousness about opening their classrooms to their peers, I think, it is important to build a non-threatening teaching environment. We need to find ways of sharing problems of practice and responding to new demands. Otherwise, we might be defensive and try to justify our teaching when certain aspects of our practice are questioned.

In spite of the strong evidence that collaborative professional development is a promising method of teacher development, teachers generally do not welcome it. Little (1982) argues that the interactions that focus on actual classroom performance are potentially the most useful yet also the most demanding because they expose how 
one teaches to the scrutiny of peers. These interactions place teachers' self-esteem and professional respect on the line. The resistance to peer sharing and observations makes an awkward and ironic contrast to the recognition that peer sharing and observations are effective forms of teacher development.

Causes for the resistance to peer sharing and observations are numerous. In the case of Korea, the culture of classroom isolation is a primary factor. As mentioned previously, teacher isolation has been the norm in Korea. Seo (2009) has noted that classrooms are usually very isolated places and there is subtle resistance from teachers against having peers in their classroom. Thus, peer sharing and collaborative learning activities, contrived or not, are rarely practiced in Korea. Teaching is often understood as a secluded activity conducted in private spaces. In such a culture, teachers are separated into classes, isolated and insulated from one another's work. The isolation may protect teachers from inspection and intrusion but it also deprives them of the opportunities to learn from and with one another, and to reflect on crucial aspects of teaching. This culture promotes reluctance among teachers to disclose their weaknesses, uncertainties, and frustrations that may be encountered in their teaching practice.

In this sense, Jeong highlighted the importance of finding a way to talk about lessons and critique the lesson, not the teacher, in order to overcome this cultural barrier. The key element in supporting teacher learning and professional development that was often cited by the participant teachers was their trustful relationship. Cheon explicitly stated that the climate of collegiality helped the teachers tackle the psychological pressure. Mutual trust, respect, and support among colleagues could even alleviate the psychological pressure brought on by appraisal. Thus, fostering collegial relationships is important in collaborative teacher learning. Collegial relationships exist when teachers discuss problems and difficulties, share ideas and knowledge, exchange techniques and approaches, observe one another's work, and collaborate on instructional projects (Little, 1982; Rosenholtz, 1989; Smylie, 1988). In schools where collegiality is the norm, these professional, interactive, supportive relationships are accepted, enhanced, and socially encouraged (Little, 1982). Such relationships have a key impact on schools and provide opportunities for teachers to work together on improvement activities.

\subsubsection{Lack of Discussion Culture}

The participant teachers suggested that providing structure to the post-lesson feedback discussion could help maximize the richness of the discussion. Lee mentioned that, when talking about the observed lesson, the participant teachers tended to focus on irrelevant features, such as the way the person looks, the sound of his voice, and the gestures he uses. Instead of attention to such superficial features of teaching, she wanted more support to direct their attention to salient features and to talk about the details of classroom practice. Jeong also expressed frustration about the lack of analytic discussions about teaching issues and dilemmas that she really wanted to share with her peer teachers, and stated that she was not getting as much out of her participation in this learning process as what she anticipated. Similarly, Cheon indicated the challenges of teacher professional development in her following reflection:

Discussions revolved around praising the teacher being observed. Comments often began, "I really liked the way you teach"... Most comments and feedback mainly remained an appraisal activity. The discussion was also limited to questioning techniques, order of activities, clarity of explanations, and so on. I expected a deeper, more insightful discussion about the lesson itself. Yet, we didn't get into engaging in a professional dialogue about teaching issues and challenging problems. ... To make teachers' professional development successful and a pleasant experience for teachers, I think, it should be a place where participant teachers share each other's dilemmas and issues they have encountered in their teaching practice, beyond an appraisal activity.

When Cheon opened her lesson to others, she clearly wanted her peer teachers to take a critical look at what she was doing in the classroom and have more critical feedback on her teaching. She professed that she did not feel that her participation in this collaborative learning project had any significant impact on her classroom practice; although, she does feel some sort of responsibility to continue to be involved.

These remarks from the participant teachers reveal that what is most difficult about the collaborative learning process is for teachers to move beyond simply looking at the teaching practice to actually seeing what is of value in this teaching and analyzing it carefully. This obstacle may be related to Korean teachers' bureaucratic working ethos that has taught teachers to be compliant and rule-governed, and not to ask questions, seek alternatives, or deal with competing values on their own (Kim, 2003). In this culture, Korean teachers are supposed to follow orders from those at the top and render them devoid of any analysis of education itself. They have remained locked in their own unquestioned and unquestioning value systems behind the closed doors of the classroom. Korean teachers are unfamiliar with expressing their own doubts and concerns related to their teaching practice 
and working together to improve it. The bureaucracy discourages Korean teachers from seeking and giving advice among themselves and leads them to shy away from colleagues' judgment and criticism.

Given this atmosphere, there is rarely a culture in schools that promotes professional talk about work and its improvement. Advice-giving, technique-trading, and materials-sharing have formed the bulk of professional activity concerned with immediate, short-term, and practical issues to the exclusion of inquiry into the principles of teaching or ethics. Here, the major elements of the prevailing norms of bureaucracy are left intact, and systematic reflective practice is not embraced. The success of professional development within this context will depend on transforming the existing managerial climate to a more collaborative culture in which failure, mistakes, and uncertainty in work are not protected and defended but are openly shared, discussed, and examined in order to provide support and help (Dudley, 2013; Fullan \& Hargreaves, 1991).

\section{Conclusion}

The participant teachers tended to agree that their experiences with this learning process had effectively enhanced their teaching quality, mutual communication, and rich understanding of their teaching practice. This learning opportunity enabled them to create a free discussion of ideas, to challenge others' and their own way of thinking, to create a culture of peer learning, and to embody an inquiry stance toward teaching. When asked whether they are still willing to support their schools in the development of this learning opportunity even when they considered the time they had invested, the psychological pressure and pitfalls they had felt, and the lack of authentic discussion, their answers were mostly positive.

Clearly, to make this teacher learning program a successful and pleasant experience for teachers, it has to be clear to teachers that the aim of classroom observation is not to assess their performance in a particular lesson. In Korea, the practice of classroom observation is still a rather new practice. Participant teachers need to develop the mindset that constructive criticism is a welcome method to improve their teaching, and provide appropriate feedback about observed lessons. If Korean practitioners are clear about these points, teachers may be less nervous about opening their classes for their peers. In terms of time constraints, school administrators need to support participant teachers by providing teacher development time and obtaining substitute coverage. Finally, we suggest continued research on teacher learning that can help specify productive ways of developing teacher learning programs for their professional growth. This research will provide us with a better understanding of what is required for teachers to adopt the position of reflective practitioners with inquiry stances toward teaching.

Finally, we recommend taking more cases for further research. The obvious strength of this study is that it helps us to understand the various aspect of the particular situation being studied, yet it still has a limitation that the data collected cannot necessarily be generalized to the wider population. It is a well known fact that each person has a different outlook towards various events thus result into different outlook for the same problem and finds different solutions. Thus, it would be valuable to compare different cases and different perspectives for the same issues raised in this study in the future studies.

\section{Acknowledgments}

This work was supported by the National Research Foundation of Korea Grant funded by the Korean Government (NRF-2013S1A3A2042899).

\section{References}

Ball, D., \& Cohen, D. (1999). Developing practice, developing practitioners: Towards a practice-based theory of professional education. In L. Darling-Hammond, \& G. Sykes (Eds.), Teaching as the learning profession: Handbook on policy and practice (pp. 3-32). San Francisco, CA: Jossey-Bass.

Baumfield, V., \& Butterworth, M. (2005). Developing and sustaining professional dialogue about teaching and learning in schools. Journal of In-Service Education, 31(2), 297-311. http://dx.doi.org/10.1080/13674580500200361

Bogdan, R., \& Biklen, S. (2003). Qualitative research for education: An introduction to theories and methods (4th ed.). Boston: Allyn \& Bacon.

Borko, H. (2004). Professional development and teacher learning: Mapping the terrain. Educational Researcher, 33(8), 3-15. http://dx.doi.org/10.3102/0013189X033008003

Brown, J., \& Duguid, P. (1998). Organizing knowledge. California Management Review, 40(3), 90-111. http://dx.doi.org/10.2307/41165945

Butler, D., \& Schnellert, L. (2008). Bridging the research-to-practice divide: Improving outcomes for students. 
Education Canada, 48(5), $\quad 36-40 . \quad$ Retrieved $\quad$ from http://www.cea-ace.ca/sites/cea-ace.ca/files/EdCan-2008-v48-n5-Butler.pdf

Campbell, A., McNamara, O., \& Gilroy, P. (2004). Practitioner research and professional development in education. London: Paul Chapman Publications.

Cho, D. (1999). A study on "linker" and "change agent" in implementing the Korean national curriculum. The Journal of Curriculum Studies, 17(2), 191-207.

Cochran-Smith, M., \& Lytle, S. (1993). Research on teaching and teacher research: The issues that divide. Educational Researcher, 19(2), 2-11. http://dx.doi.org/10.3102/0013189X019002002

Cochran-Smith, M., \& Lytle, S. (1999). The teacher research movement: A decade later. Educational Researcher, 28(7), 15-25. http://dx.doi.org /10.3102/0013189X028007015

Cochran-Smith, M., \& Lytle, S. (2009). Inquiry as stance: Practitioner research in the next generation. New York: Teachers College Press.

Cohen, D., \& Hill, H. (2000). Instructional policy and classroom performance: The mathematics reform in California. Teachers College Record, 102(2), 296-345. http://dx.doi.org/10.1111/0161-4681.00057

Cowley, K., \& Meehan, L. (2001). Assessing teacher efficacy and professional learning community in 19 elementary and high schools. Paper presented at the Annual Meeting of the CREAT National Evaluation Institute, Wilmington, NC.

Destigter, T. (2004). Inquiry as a mode of living: A teacher's transaction with John Dewey. English Education, 36(4), 318-323. Retrieved from http://search.proquest.com/docview/214375677/fulltextPDF/70F757527CCB4F4DPQ/6?accountid=6802

Dewey, J. (1938). Experience and education. New York: Macmillan.

Dudley, P. (2013). Teacher learning in lesson study: What interaction-level discourse analysis revealed about how teachers utilised imagination, tacit knowledge of teaching and fresh evidence of pupils learning, to develop practice knowledge and so enhance their pupils' learning. Teaching and Teacher Education, 34(6), 107-121. http://dx.doi.org/10.1016/j.tate.2013.04.006

Emery, W. (1996). Teachers' critical reflection through expert talk. Journal of Teacher Education, 47(2), 110-119. http://dx.doi.org/10.1177/0022487196047002004

Erickson, G., Brandes, G., Mitchell, I., \& Mitchell, J. (2005). Collaborative teacher learning: Findings from two professional development projects. Teaching and Teacher Education, 21(7), 787-798. http://dx.doi.org/10.1016/j.tate.2005.05.018

Fahey, L., \& Prusak, L. (1998). The eleven deadliest sins of knowledge management. California Management Review, 40(3), 265-276. http://dx.doi.org/10.2307/41165954

Fecho, B., Price, K., \& Read, C. (2004). From Tununak to Beaufort: Taking a critical inquiry stance as a first year teacher. English Education, 36(4), 263-288. Retrieved from http://search.proquest.com/docview/214375625/fulltextPDF/621BC399B87C45C3PQ/4?accountid=6802

Fullan, M. (2000). The return of large-scale reform. Journal of Educational Change, 1(1), 5-27. http://dx.doi.org/10.1023/A:1010068703786

Fullan, M. (2001). Leading in a culture of change. San Francisco, CA: Jossey-Bass.

Fullan, M., \& Hargreaves, A. (1991). What's worth fighting for? Working together for your School. Andover, MA: The Regional Laboratory for Educational Improvement of the Northeast and Islands. Retrieved from http://files.eric.ed.gov/fulltext/ED342128.pdf

Fullan, M., \& Miles, M. (1992). Getting reform right: What works and what doesn't. Phi Delta Kappan, 73(10), 744-752. http://search.proquest.com/docview/218481450/fulltext/CA9CC022235B4776PQ/8?accountid=6802

Garet, M. (2001). What makes professional development effective? Results from a national sample of teachers. American Educational Research Journal, 38(4), 915-945. http://dx.doi.org/10.1080/17508480903450232

Hardy, I. (2010). Critiquing teacher professional development: Teacher learning within the field of teachers' work. Critical Studies in Education, 51(1), 71-84. http://dx.doi.org/10.1080/17508480903450232

Hiebert, J., Gallimore, R., \& Stigler, J. (2002). A knowledge base for the teaching profession: What would it look 
like and how can we get one? Educational Researcher, 31(5), 3-15. http://dx.doi.org/10.3102/0013189X031005003

Hobson, D. (2001). Action and reflection: Narrative and journaling in teacher research. In G. Burnaford, J. Fischer, \& D. Hobson (Eds.), Teachers doing research: The power of action through inquiry (pp. 7-28). Mahwah: Erlbaum.

Hord, S. (1997). Professional learning communities: Communities of continuous inquiry and improvement. Austin, TA: Southwest Educational Development Laboratory. Retrieved from https://connect2mathconnect2science.pbworks.com/f/Hord_PLCs.pdf

Horn, I., \& Little, J. (2010). Attending to problems of practice: Routines and resources for professional learning in teachers' workplace interactions. American Educational Research Journal, 47(1), 181-217. http://dx.doi.org/10.3102/0002831209345158

Hourcade, J., \& Bauwens, J. (2002). Cooperative teaching: Rebuilding and sharing the schoolhouse. Austin, TX: PRO-ED.

Kazemi, E., \& Hubbard, A. (2008). New directions for the design of professional development: Attending to the coevolution of teachers' participation across contexts. Journal of Teacher Education, 59(5), 428-441. http://dx.doi.org/10.1177/0022487108324330

Kennedy, M. (1998). Form and substance in inservice teacher education. Madison, WI: National Institute for Science Educaiton. Retrieved from http://files.eric.ed.gov/fulltext/ED472719.pdf

Kim, B. (2003). A qualitative case study on the middle school teachers' cultures of the teaching profession. The Journal of Educational Administration, 21(1), 1-27.

Kim, H. (2007). Assessment of elementary teachers for an in-service, practical arts education program. Journal of Korean Practical Arts Education, 20(2), 133-153.

Kim, S., \& Cheon, S. (2011). An analysis of the work time of secondary school teacher for the NEIS academic affairs. The Journal of Korean Teacher Education, 28(3), 127-152.

Lave, J., \& Wenger, E. (1991). Situated learning: Legitimate peripheral participation. Cambridge: University of Cambridge Press. http://dx.doi.org/10.1017/CBO9780511815355

Lincoln, Y. S., \& Guba, E. G. (1985). Naturalistic inquiry. Beverly Hills, CA: Sage.

Little, J. (1982). Norms of collegiality and experimentation: Workplace conditions of school success. American Educational Research Journal, 19(3), 325-340. http://dx.doi.org/10.3102/00028312019003325

Louis, K., Kruse, S., \& Bryk, A. (1995). Professionalism and community: What is it and why is it important in urban schools? In K. Louis, \& S. Kruse (Eds.), Professionalism and community: Perspective on reforming urban schools (pp. 3-22). Thousand Oaks, CA: Sage Publications.

McLaughlin, M., \& Talbert, J. (2006). Building school-based teacher learning communities: Professional strategies to improve student achievement. New York: Teachers College Press.

Merriam, S. (1998). Qualitative research and case study applications in education. San Francisco, CA: Jossey-Bass.

Miles, M., \& Huberman, A. (1994). Data management and analysis methods. Thousand Oaks, CA: Sage Publications.

Mitchell, I. (2000). Moving from professional talk to teacher research. Paper presented at the Annual Meeting of the American Education Research Association, New Orleans. Retrieved from http://resources.educ.queensu.ca/ar/aera2000/mitchell.pdf

Newman, F., \& Wehlage, G. (1995). Successful school restructuring: A report to the public and educators by the center on organization and restructuring schools. Madison, WI: Wisconsin Center for Education Research. Retrieved

from http://assets00.grou.ps/0F2E3C/wysiwyg_files/FilesModule/s2624971assignment2/20101024042032-llqlsoj utnnvvasqs/teaching.pdf

Opfer, V. D., \& Pedder, D. (2010). Benefits, status and effectiveness of continuous professional development for teachers in England. The Curriculum Journal, 21(4), 413-431. http://dx.doi.org/10.1080/09585176.2010.529651

Park, S., \& Lee, S. (2012). A qualitative study of the burden of teachers in administrative affairs and policy 
agendas enhancing instructional abilities of teachers. The Journal of Korean Teacher Education, 29(1), 371-396.

Pugach, M., \& Johnson, L. (1990). Developing reflective practice through structured dialogue. In R. Clift, W. Houston, \& M. Pugach (Eds.), Encouraging reflective practice in education: An analysis of issues and programs (pp. 186-207). New York: Teachers College Press.

Putnam, R., \& Borko, H. (2000). What do new views of knowledge and thinking have to say about research on teacher learning? Educational Researcher, 29(1), 4-15. http://dx.doi.org/10.3102/0013189X029001004

Rosenholtz, S. (1989). Teachers'workplace: The social organization of schools. New YorkL: Longmans.

Schon, D. (1983). The reflective practitioner. New York: Basic Books.

Seo, K. (2009). Teacher learning communities and professional development. The Journal of Korean Teacher Education, 26(2), 243-276.

Smylie, M. (1988). The enhancement function of staff development: Organizational and psychological antecedents to individual teacher change. American Educational Research Journal, 25(1), 1-30. http://dx.doi.org/10.3102/00028312025001001

Snow-Gerono, J. (2005). Naming inquiry: PDS teachers' perceptions of teacher research and living and inquiry stance toward teaching. Teacher Education Quarterly, 32(4), 79-95. Retrieved from http://eds.b.ebscohost.com/ehost/pdfviewer/pdfviewer?sid=983dff6a-22f0-42dc-a889-49f0dfdd6ba0\%40ses sionmgr113\&vid=4\&hid $=106$

So, K. (2013). Knowledge construction among teachers within a community based on inquiry as stance. Teaching and Teacher Education, 29, 188-196. http://dx.doi.org/10.1016/j.tate.2012.10.005

Spillane, J. (1999). External reform initiatives and teachers' efforts to reconstruct their practice: The mediating role of teachers' zones of enactment. Journal of Curriculum Studies, 31(2), 143-175. http://dx.doi.org/10.1080/002202799183205

Timperley, H., Wilson, A., Barrar, H., \& Fung, I. (2007). Teacher professional learning and development: Best evidence synthesis iteration. Wellington: New Zealand Ministry of Education.

Valli, L. (1997). Listening to other voices: A description of teacher reflection in the United States. Peabody Journal of Education, 72(1), 67-88. http://dx.doi.org/10.1207/s15327930pje7201_4

Wenger, E. (1998). Communities of Practice: Learning, Meaning, and Identity. New York: Cambridge University Press. http://dx.doi.org/10.1017/CBO9780511803932

Wilson, S. (2013). Professional development for science teachers. Science, 340, $310-313$. http://dx.doi.org/10.1126/science. 1230725

Zuidema, A. (2012). Making space for informal inquiry: Inquiry as stance in an online induction network. Journal of Teacher Education, 63(2), 132-146. http://dx.doi.org/10.1177/0022487111428326

\section{Note}

Note 1 . The interview was originally conducted in Korean and first translated by one of the authors. To secure the accuracy of the translation, an educational researcher bilingual in Korean and English translated it again. The best translations were chosen by drawing agreements from the comparison of two versions.

\section{Copyrights}

Copyright for this article is retained by the author(s), with first publication rights granted to the journal.

This is an open-access article distributed under the terms and conditions of the Creative Commons Attribution license (http://creativecommons.org/licenses/by/3.0/). 